\title{
Chemical composition, antioxidant, antimicrobial and antiviral activities of the leaf extracts of Syzygium myrtifolium
}

\author{
MUSTAFFA ALBAKRI AHMAD ${ }^{1}$ \\ YI HUI LIM ${ }^{1}$ \\ YIK SIN CHAN ${ }^{1}$ \\ CHUN-YUAN HSU ${ }^{2}$ \\ TZONG-YUAN WU ${ }^{2}$ \\ NAM WENG SIT ${ }^{1, *}$ \\ ${ }^{1}$ Department of Allied Health Sciences \\ Faculty of Science, Universiti Tunku \\ Abdul Rahman, Bandar Barat, 31900 \\ Kampar, Perak, Malaysia \\ ${ }^{2}$ Department of Bioscience Technology \\ College of Science, Chung Yuan Christian \\ University, Chung Li District, Taiwan \\ 32023, R.O.C.
}

\begin{abstract}
This study was conducted to evaluate the chemical composition and biological activities of the leaf extracts of Syzygium myrtifolium Walp. (Myrtaceae). The results indicate that the leaf extracts of $S$. myrtifolium contain various classes of phytochemicals (alkaloids, anthraquinones, flavonoids, phenolics, saponins, tannins and triterpenoids) and possess antioxidant, antibacterial, antifungal and antiviral activities. Ethyl acetate, ethanol, methanol, and water extracts exhibited significantly higher $(p<0.05)$ oxygen radical absorbance capacity and ferric-reducing antioxidant power than the hexane and chloroform extracts. However, all extracts exhibited stronger inhibitory activity against four tested species of yeasts (minimal inhibitory concentration: $0.02-0.31 \mathrm{mg} \mathrm{mL}^{-1}$ ) than against six tested species of bacteria (minimal inhibitory concentration: $0.16-1.25 \mathrm{mg} \mathrm{mL}^{-1}$ ). The ethanolic extract offered the highest protection of Vero cells (viability $>70 \%$ ) from the cytopathic effect caused by the Chikungunya virus while the ethyl acetate extract showed significant replication inhibitory activity against the virus $(p<0.001)$ using the replicon-enhanced green fluorescent protein reporter system.
\end{abstract}

Keywords: Syzygium myrtifolium leaf, antibacterial, antifungal, antioxidant, Chikungunya virus, recombinant baculovirus

Syzygium myrtifolium Walp (synonyms Syzygium campanulatum, Eugenia oleina) is an angiosperm, perennial, evergreen shrub or tree belonging to the family Myrtaceae. It is known by many vernacular names such as red wood, red lip, wild cinnamon, 'kelat oil', and 'kelat paya' (1). The plant is native to India, Myanmar, Thailand, Indonesia, Malaysia, the Philippines, and Singapore. It is usually grown as a hedge and occasionally used as a stomachic in traditional medicine (2).

The ethanol extracts of the leaves of S. myrtifolium have been reported to have cytotoxic activity against human colon cancer (HT-29) cell line (2). The methanol extract of the leaves possesses antiangiogenic activity (3) and cytotoxic effects on breast cancer (MCF-7) and colorectal carcinoma (HCT-116) cell lines (4). The methanol extracts of the leaves and

\footnotetext{
*Correspondence; e-mail address: sitnw@utar.edu.my
} 
stems were found to have inhibitory activity against dengue virus NS2b/NS3 protease (5). Two flavanones, (2S)-7-hydroxy-5-methoxy-6,8-dimethyl-flavanone and desmethoxymatteucinol), two triterpenoids (betulinic and ursolic acid, and a chalcone (E)-2',4'-dihydroxy-6'-methoxy-3,5'-dimethylchalcone) have been isolated from the leaves $(2,6)$.

Oxidative stress causes mitochondrial dysfunction and oxidation to biomolecules, leading to the onset and/or progression of metabolic disorders, cancer, diabetes, and cardiovascular diseases (7). Also, infections of various origins are among the major contributors to global morbidity and mortality $(8,9)$. The Chikungunya virus (CHIKV) is a virus causing Chikungunya fever, typically with acute and chronic musculoskeletal pain in humans. This virus is transmitted by Aedes mosquitoes (10). Since many patients are not reporting to healthcare facilities, the incidence of cases is likely underestimated or the patients are treated only symptomatically since there are no specific drugs against the virus.

In an attempt to explore the plant Syzygium myrtifolium Walp for more biological activities, this study was conducted to characterise its leaves for antioxidant, antibacterial, antifungal, and antiviral activities, as well as for chemical composition.

\section{EXPERIMENTAL}

\section{Chemicals}

The following chemicals were used in the study: amphotericin B from Bio Basic (Canada), Roswell Park Memorial Institute-1640 medium from Biowest (USA), 2,2-diphenyl-1-picrylhydrazyl (DPPH) and 3-(N-morpholino)propanesulfonic acid from Calbiochem (Germany), chloramphenicol from Duchefa Biochemie (The Netherlands), foetal bovine serum, penicillin-streptomycin solution, trypan blue, and trypsin-EDTA solution from Gibco (USA), Mueller-Hinton agar and Mueller-Hinton broth from HiMedia (India), potato dextrose agar from Laboratorios Conda (Spain), ethyl acetate (AR grade), ferric(III) chloride hexahydrate, Sabouraud dextrose agar, Dragendorff's reagent, and sodium acetate from Merck (Germany), chloroquine diphosphate salt from MP Biomedicals (USA), 2,4,6-tripyridyl-s-triazine from Nacalai Tesque (Japan), Dulbecco's modified Eagle's medium (DMEM), Dulbecco's phosphate buffered saline, fluorescein sodium salt, gelatine, neutral red solution, $p$-iodonitrotetrazolium chloride, sodium bicarbonate, and tetracycline hydrochloride from Sigma-Aldrich (USA), ferrous sulphate heptahydrate from Loba Chemie (India), hexane, $95 \%$ ethanol, chloroform, methanol (all of AR grade), and 6-hydroxy-2,5,7,8-tetramethylchroman-2-carboxylic acid (Trolox) from Thermo Fisher Scientific (USA).

\section{Sample processing}

Approximately $1 \mathrm{~kg}$ of the green fresh leaves of S. myrtifolium was collected from a herbs and spices farm in Pagoh (Johor, Malaysia) in January 2014 and transported instantly to the laboratories for processing. The identity of the plant was confirmed by an ethnobotanist (Professor Hean Chooi Ong from the University of Malaya, Malaysia). A specimen voucher of the leaves was prepared, labelled as UTAR/FSC/14/001, and deposited at the Kampar Campus, Universiti Tunku Abdul Rahman (Malaysia).

The leaves were cleaned with tap water and blended into small pieces prior to solvent extraction. The samples were extracted sequentially with hexane, chloroform, ethyl acetate, 
ethanol, methanol, and water. The maceration process was performed at ambient temperature with agitation at a speed of $120 \mathrm{rpm}$ for $24 \mathrm{~h}$. This process was repeated twice. The organic solvent filtrates were pooled together and dried at $40^{\circ} \mathrm{C}$ using a rotary evaporator while the water was removed using a freeze-dryer. The dry extracts were stored at $-20{ }^{\circ} \mathrm{C}$ prior to analysis.

\section{Phytochemical screening}

Each extract was screened for the presence of alkaloids (Dragendorff's test), anthraquinones, flavonoids (Shinoda test), saponins (foam test), tannins (gelatine test), phenolics (ferric chloride test), and triterpenoids (Salkowski test) (11).

\section{Total phenolic content (TPC) and total flavonoid content (TFC) assays}

The TPC and TFC of each extract were measured, in triplicate, based on the Folin-Ciocalteu method and aluminium chloride method, resp. (12) with modifications. The extract solution was prepared as $10 \mathrm{mg} \mathrm{mL}^{-1}$ in a methanol-water mixture $(2: 1, V / V)$. Gallic acid $\left(2.5,5,10,20,40,80,160\right.$, and $\left.320 \mu \mathrm{g} \mathrm{mL} \mathrm{m}^{-1}\right)$ was used as a standard for TPC assay. Quercetin standard solutions $\left(25,50,100,200,300,400\right.$, and $\left.500 \mu \mathrm{g} \mathrm{mL}^{-1}\right)$ were used to generate a calibration curve for the TFC assay. The methanol-water mixture (2:1, $V / V)$ was used as a negative control. The microplate was incubated in the dark at room temperature for $90 \mathrm{~min}$ (TPC) or $60 \mathrm{~min}$ (TFC). The absorbance was measured at $765 \mathrm{~nm}$ for TPC and $420 \mathrm{~nm}$ for TFC using a microplate reader (FLUOstar ${ }^{\circledR}$ Omega, BMG Labtech, Australia). The TPC and TFC values for each extract were expressed as $\mathrm{mg}$ gallic acid equivalent (GAE) $\mathrm{g}^{-1}$ sample and $\mathrm{mg}$ quercetin equivalent $(\mathrm{QE}) \mathrm{g}^{-1}$ sample, resp.

\section{Antioxidant assays}

2,2-diphenyl-1-picrylhydrazyl (DPPH) radical scavenging assay. - The DPPH radical scavenging assay was adapted from the method of Pavithra and Vadivukkarasi (13). Six concentrations $(31.3,62.5,125,250,500$, and $1000 \mu \mathrm{g} \mathrm{mL}-1)$ were prepared for each extract in a methanol/water mixture $(2: 1, V / V)$. Ascorbic acid was used as a positive control. Extract solution with different concentrations without the addition of DPPH was used as a sample blank while DPPH solution without the presence of extract served as a control. The absorbance $(A)$ value was recorded at $517 \mathrm{~nm}$ using the microplate reader. The assay was performed in triplicate. The percentage of inhibition was calculated as $\left\{1-\left[\left(A_{\text {sample }}-A_{\text {sample blank }}\right) /\right.\right.$ $\left.\left.A_{\text {control }}\right]\right\} \times 100$ and plotted against the concentration of extract. The half-maximal inhibitory concentration was then determined from the plot.

Ferric-reducing antioxidant power (FRAP) assay. - The FRAP assay was conducted using the method of Yang et al. (14) with modifications. Three concentrations for each extract, i.e., 250,500 , and $1000 \mu \mathrm{g} \mathrm{mL}^{-1}$, were tested. A series of ferrous sulphate solutions $(0.1,0.2,0.4$, $0.8,1.2,1.6$, and $2.0 \mathrm{mmol} \mathrm{mL}^{-1}$ ) was used to generate a standard curve. Extract solutions without the addition of FRAP reagent served as a sample blank. The absorbance was measured at $593 \mathrm{~nm}$. The FRAP value for each extract was calculated based on the ferrous sulphate standard curve and expressed as a mmol Fe(II) equivalent $\mathrm{g}^{-1}$ sample. The assay was carried out in triplicate. 
Oxygen radical absorbance capacity (ORAC) assay. - The ORAC of the extracts was assayed using a fluorometric method, as described previously (15). Each extract was prepared at 900 $\mu \mathrm{g} \mathrm{mL} \mathrm{m}^{-1}$ in $75 \mathrm{mmol} \mathrm{L}^{-1}$ sodium phosphate buffer ( $\mathrm{pH} 7.0$ ) and two-fold serially diluted in 96-well black microplate to produce six concentrations $(3.13,6.25,12.5,25,50$, and 100 $\mu \mathrm{g} \mathrm{mL} \mathrm{L}^{-1}$ ) for evaluation. Trolox standard curve was constructed using five concentrations $\left(0.78,1.56,3.13,6.25\right.$, and $\left.12.5 \mathrm{nmol} \mathrm{mL}^{-1}\right)$. The fluorescence intensity at the excitation wavelength of $485 \mathrm{~nm}$ and emission wavelength of $520 \mathrm{~nm}$ for each well was then monitored using the microplate reader at an interval of $1.5 \mathrm{~min}$ for $60 \mathrm{~min}$. The net area under the fluorescence decay curve $(A U C)$ for standard or sample was calculated after subtraction of AUC of sodium phosphate buffer, which served as a blank. The ORAC value for each extract was interpolated from the Trolox standard curve and expressed as a mmol Trolox equivalent (TE) $\mathrm{g}^{-1}$ sample.

\section{Antibacterial and antifungal assays}

The extracts were evaluated for antimicrobial activities using a colorimetric broth microdilution method with $p$-iodonitrotetrazolium chloride as a microbial growth indicator (15). A panel of human pathogens, consisting of two species of Gram-positive bacteria (Bacillus cereus $\mathrm{ATCC}^{\circledR} 11778^{\mathrm{TM}}$ and Staphylococcus aureus $\left.\mathrm{ATCC}^{\circledR} 6538^{\mathrm{TM}}\right)$, four species of Gram-negative bacteria (Acinetobacter baumannii ATCC $^{\circledR} 19606^{\mathrm{TM}}$, Escherichia coli ATCC $^{\circledR} 35218^{\mathrm{TM}}$, Klebsiella pneumoniae $\mathrm{ATCC}^{\circledR} 13883^{\mathrm{TM}}$, and Pseudomonas aeruginosa $\mathrm{ATCC}^{\circledR} 27853^{\mathrm{TM}}$ ), four species of yeasts (Candida albicans ATCC ${ }^{\circledR} 90028^{\mathrm{TM}}$, Candida krusei ATCC ${ }^{\circledR} 6258^{\mathrm{TM}}$, Candida parapsilosis ATCC $^{\circledR} 22019^{\mathrm{TM}}$, and Cryptococcus neoformans ATCC $90112^{\mathrm{TM}}$ ), and a filamentous fungus (Aspergillus fumigatus ATCC ${ }^{\circledR} 204305^{\mathrm{TM}}$ ), was used in the assays. All microbial strains were purchased from the American Type Culture Collection (Manassas, VA, USA). A two-fold serial dilution was performed, and each extract was evaluated at eight concentrations, ranging from 0.02 to $2.50 \mathrm{mg} \mathrm{mL}^{-1}$. Chloramphenicol and tetracycline hydrochloride were used as positive controls for antibacterial assay whereas amphotericin B was used for the antifungal assay. The minimal inhibitory concentration, minimal bactericidal concentration, and minimal fungicidal concentration were determined, in triplicate, for each extract.

\section{Antiviral assays}

Cytopathic effect inhibition assay. - The plant extracts were also assessed for antiviral activity against CHIKV using the method of Chan et al. (16). The virus used was provided by Professor Shamala Devi from the University of Malaya (Malaysia) and was of the Asian genotype with an accession number of EU703761. The virus was propagated in the African monkey kidney epithelial (Vero) cells $\left(\mathrm{ATCC}^{\circledR} \mathrm{CCL}-81^{\mathrm{TM}}\right.$ ) and harvested after the cytopathic effect had developed. The cytotoxicity of the leaf extracts of S. myrtifolium on the Vero cells has been determined and reported elsewhere (17). Thus, only non-toxic concentrations of the extracts were used in the cytopathic effect inhibition assay. The starting concentration for hexane, chloroform, ethyl acetate, ethanol, methanol, and water extracts were 20, 20, 10, 512, 512 , and $320 \mu \mathrm{g} \mathrm{mL}^{-1}$, resp. Extracts of different concentrations were added to the Vero cells together with the virus at a multiplicity of infection of one and incubated at $37^{\circ} \mathrm{C}$ and $5 \%$ $\mathrm{CO}_{2}$ for $72 \mathrm{~h}$. Medium (DMEM only), virus (cells treated with virus only), cell (cells with medium only), and positive control (chloroquine; $0.39-12.4 \mu \mathrm{mol} \mathrm{L}^{-1}$ ) were incorporated into each microplate. The cell viability was measured by neutral red uptake assay (18). The assay was performed in three independent experiments with duplicates for each experiment. The 
half-maximal effective concentration of each extract was interpolated from the plot of percentage of cell viability against the concentration of extract.

Replication inhibition assay. - In order to establish a safe and convenient assay for antiCHIKV replication, a modified baculovirus gene delivery technology was applied to the transient expression of non-structural proteins of CHIKV (nsP1-nsP4) with the subgenomic promoter controlling the expression of enhanced green fluorescent protein (EGFP). Briefly, U-2 OS cells $\left(1 \times 10^{5}\right.$ cells per well) were seeded in a 24-well microplate and transduced with the vAc-CMV-CHIKV NS-EGFP at a multiplicity of infection of 20 for $2 \mathrm{~h}$. The supernatant with the recombinant baculovirus was removed, and the plant extracts were added and incubated for $72 \mathrm{~h}$. The cells were then harvested, and the EGFP was extracted. The fluorescence activity was monitored using a fluorescence spectrophotometer (Cary Eclipse, Varian Optical Spectroscopy Instruments, Australia) and normalised with the activity of dimethyl sulfoxide (negative control), as reported previously (19).

\section{Data analysis}

The data were analysed for statistical significance using the IBM SPSS Statistics for Windows Version 23.0 software (IBM Corp., NY, USA). One-way analysis of variance (ANOVA) was used, followed by post-hoc tests, either with Tukey's honestly significant difference test for equal variance assumed or Dunnett's T3 test for equal variance not assumed. Pearson correlation test was used to examine the correlations between TPC or TFC with DPPH radical scavenging activity, FRAP, and ORAC values. The significance level $(\alpha)$ was set at 0.05 .

\section{RESULTS AND DISCUSSION}

\section{Phytochemical analysis}

Phytochemical analysis indicated that the leaves of S. myrtifolium contained alkaloids, anthraquinones, flavonoids, phenolics, saponins, tannins, and triterpenoids; ethanolic and methanolic extracts contained all the seven classes of phytochemicals tested. Phenolics and triterpenoids were detected in all extracts. Anthraquinones were present in the hexane, ethyl acetate, and water extracts while tannins were found in the chloroform, ethyl acetate, and water extracts. It is clear from Table I that more polar extracts, i.e., ethanol, methanol, and water extracts showed significantly higher TPC and TFC $(p<0.05)$ than less polar extracts (hexane, chloroform, and ethyl acetate). Among these extracts, water extract had the highest TPC and TFC.

The results of the phytochemical analysis are consistent with the findings of Memon et al. (2) who reported the presence of alkaloids, flavonoids, glycosides, phenols, steroids, tannins, and terpenoids in the ethanolic and $50 \%$ hydroethanolic extracts of the leaves of S. myrtifolium. The same report gives for TPC and TFC in ethanol and water extract, 31.4 and $31.2 \%(\mathrm{~m} / \mathrm{m}) \mathrm{GAE}$, resp., and 68.8 and $44.9 \%(\mathrm{~m} / \mathrm{m}) \mathrm{QE}$, resp. Compared to individual solvent extraction done by Memon et al. (2) the present study recorded lower TPC and TFC values (24.1 and $30.4 \%(\mathrm{~m} / \mathrm{m}) \mathrm{GAE}$, resp.; 14.2 and $25.0 \%(\mathrm{~m} / \mathrm{m}) \mathrm{QE}$, resp.) for these two extracts (Table I), probably resulting from the sequential solvent extraction used. 


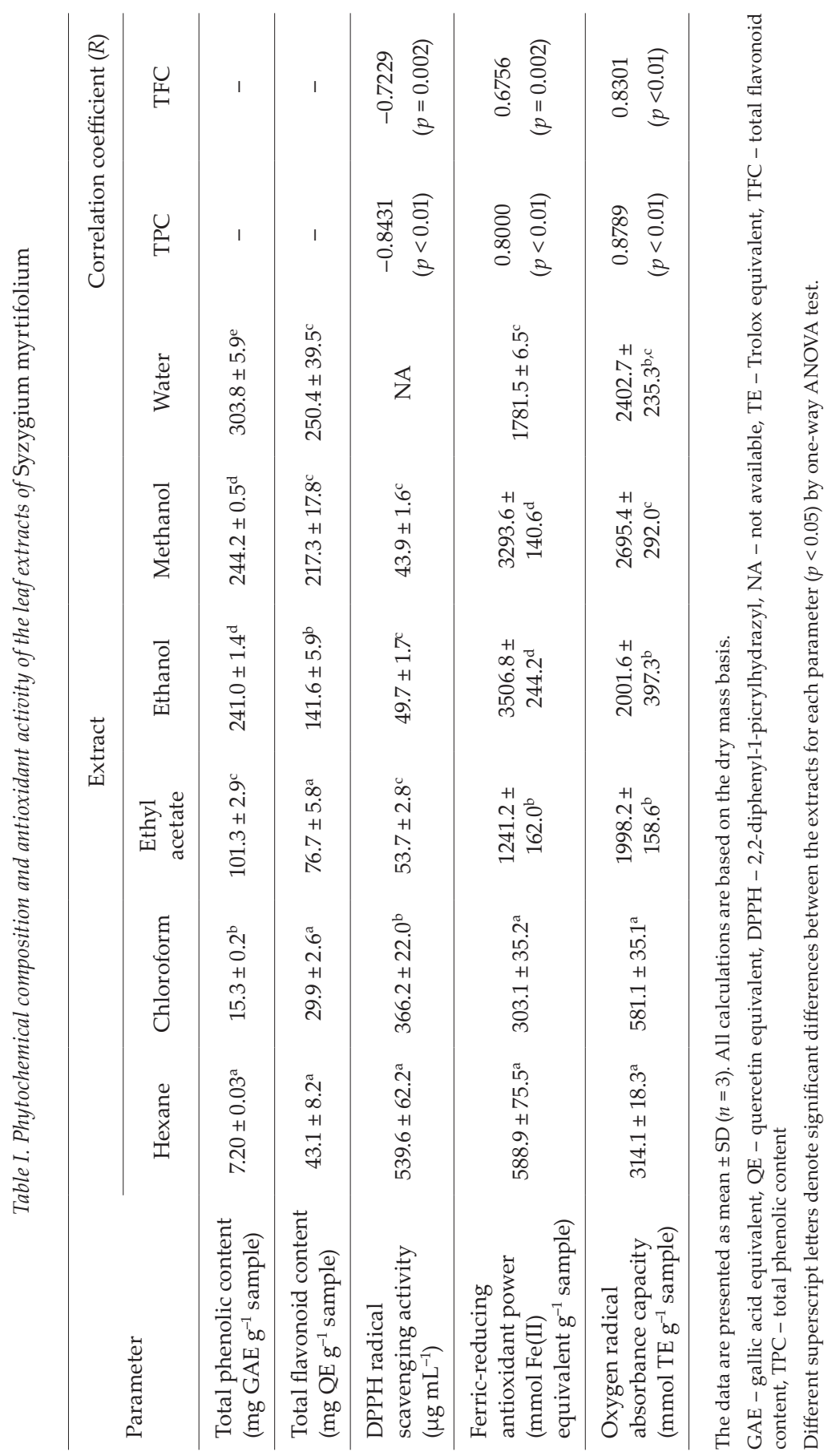




\section{Antioxidant activity}

All extracts displayed DPPH radical scavenging activity in a concentration-dependent manner (Fig. 1). As evident from Fig. 1, all the extracts, except the water one, at 250, 500, and $1000 \mu \mathrm{g} \mathrm{mL}-1$, showed significantly higher radical scavenging activity $(p<0.05)$ than the lower concentrations of $31.3,62.5$, and $125 \mu \mathrm{g} \mathrm{mL}^{-1}$. Radical scavenging activity for the water extract was not significantly different among the six concentrations evaluated (12.3$32.6 \%$ ). The ethyl acetate, ethanol, and methanol extracts possessed significantly higher radical scavenging activity $(p<0.05)$ than the other three extracts. At $1000 \mu \mathrm{g} \mathrm{mL}^{-1}$, these extracts were able to scavenge more than $92 \%$ of DPPH radicals. They thus exerted the lowest $50 \%$ inhibitory values, ranging from 43.9 to $53.7 \mu \mathrm{g} \mathrm{mL}-1$ (Table I). As for the peroxyl radical scavenging activity, the ethyl acetate, ethanol, methanol, and water extracts exhibited significantly higher $(p<0.05)$ ORAC values than hexane and chloroform extracts. The strong antioxidant activity of these extracts was further supported by their high FRAP values. Notably, although water extract exhibited high FRAP and ORAC values (Table I), the DPPH radical scavenging activity was low, with $32.5 \%$ of inhibition at $1000 \mu \mathrm{g} \mathrm{mL}^{-1}$. The TPC and TFC of the extracts showed significantly strong correlations $(p<0.01)$ with ORAC values (Table I). Desmethoxymatteucinol, one of the known flavanones in the leaves of S. myrtifolium, has been isolated from the methanol extract of Syzygium aqueum leaves and reported to have mild antioxidant activity (20).



$\rightarrow$ Hexane $\sim$ Chloroform $\rightarrow$ Ethyl acetate -- Ethanol $\rightarrow$ Methanol $\rightarrow$-Water

Fig. 1. DPPH radical scavenging activity of the leaf extracts of Syzygium myrtifolium. The results are expressed as mean $\pm \mathrm{SD}(n=3)$. 

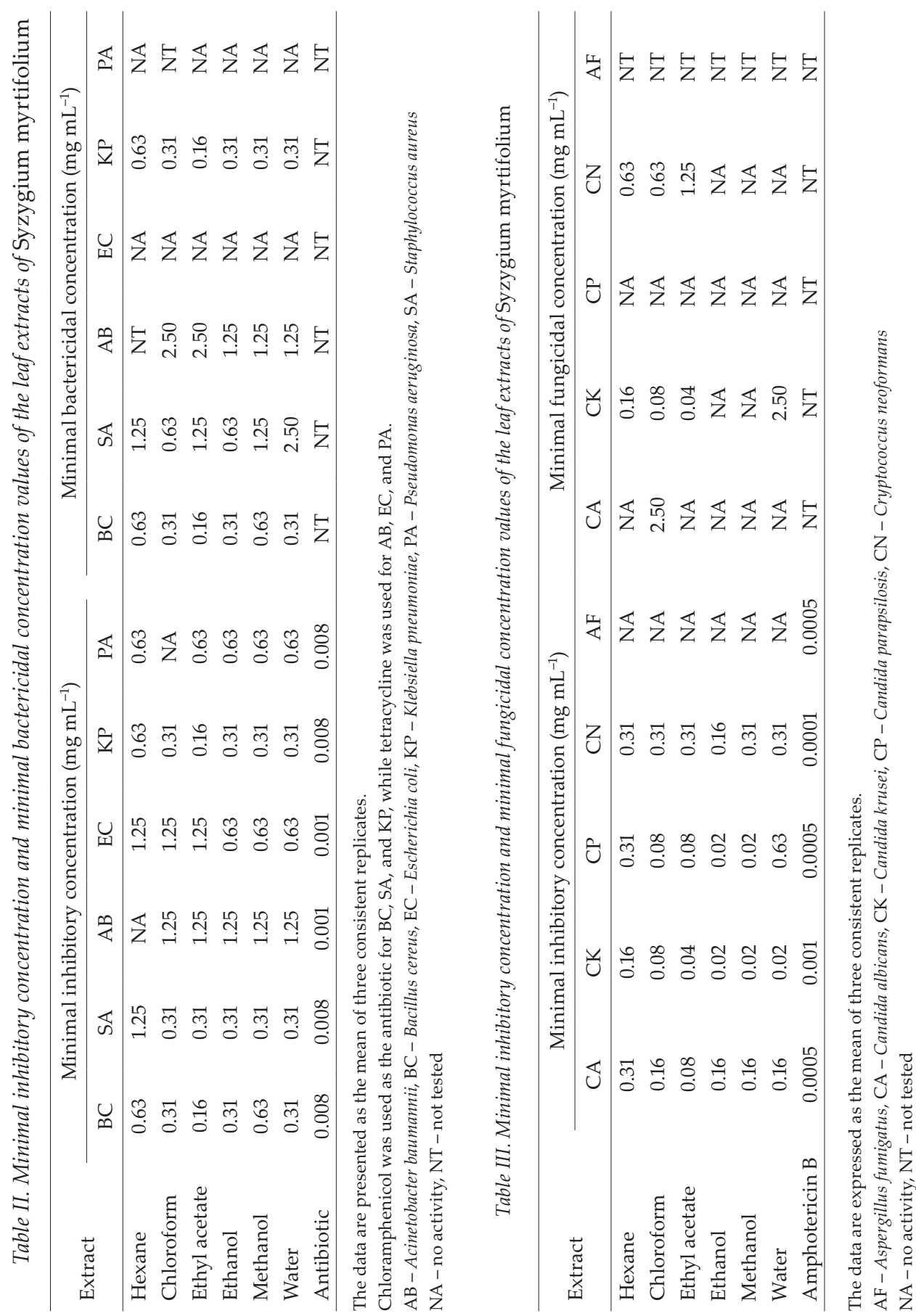


\section{Antibacterial and antifungal activities}

All extracts exhibited inhibitory activity against the six bacterial species tested, except for the hexane extract against Acinetobacter baumannii and chloroform extract against Pseudomonas aeruginosa with a minimal inhibitory concentration range of 0.16 to $1.25 \mathrm{mg} \mathrm{mL}^{-1}$. The lowest value was produced by the ethyl acetate extract against Bacillus cereus and Klebsiella pneumoniae (Table II). However, all extracts showed bactericidal activity only against B. cereus, Staphylococcus aureus, A. baumannii and K. pneumoniae (Table II).

In contrast to the results for bacterial species, all the six extracts exhibited stronger inhibitory activity against the four species of yeasts (Table III) with a lower minimal inhibitory concentration range $\left(0.02-0.31 \mathrm{mg} \mathrm{mL}^{-1}\right)$. In addition to water extract, ethanolic and methanolic extracts produced the lowest minimal inhibitory concentration against Candida krusei and Candida parapsilosis. However, the extracts showed very limited killing effects on the yeasts, mainly on C. krusei and Cryptococcus neoformans. None of the extracts showed antifungal activity against the filamentous fungus Aspergillus fumigatus. Among the extracts, ethyl acetate extract is regarded as highly active against all three species of Candida, as their minimal inhibitory concentration values were less than $0.1 \mathrm{mg} \mathrm{mL}^{-1}$. The leaf extracts of S. myrtifolium have been shown to have fungicidal properties on the dermatophytes Trichophyton spp. (17).

\section{Antiviral activity}

The hexane and chloroform extracts at $20 \mu \mathrm{g} \mathrm{mL} \mathrm{L}^{-1}$, ethyl acetate extract at 5 and $10 \mu \mathrm{g} \mathrm{mL} \mathrm{m}^{-1}$, ethanol extract at 256 and $512 \mu \mathrm{g} \mathrm{mL} \mathrm{L}^{-1}$, methanol extract at $128-512 \mu \mathrm{g} \mathrm{mL}-1$,

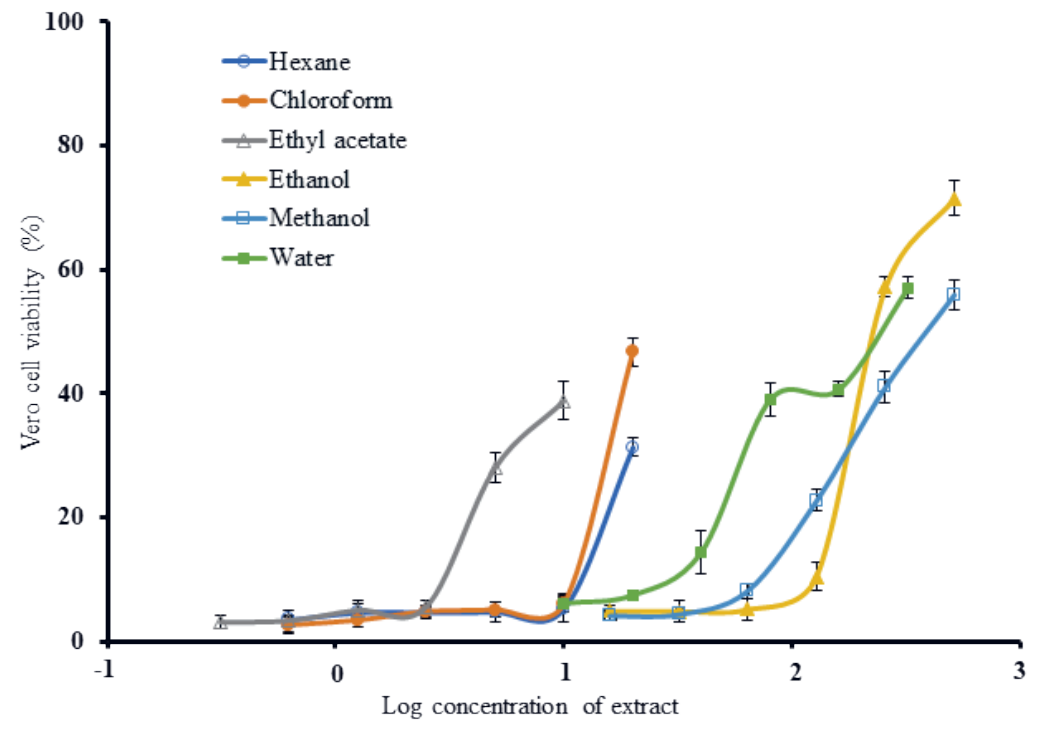

Fig. 2. Cytopathic effect inhibitory activity of the leaf extracts of Syzygium myrtifolium against Chikungunya virus. The percentage is expressed as mean $\pm \mathrm{SD}(n=3)$. 
and water extract at $40-320 \mu \mathrm{g} \mathrm{mL}-1$ enable significantly higher Vero cell viability $(p<0.05)$ compared to the lower concentrations of the respective extracts. However, only the polar extracts, i.e., ethanolic, methanolic, and water extracts were able to protect $>50 \%$ of Vero cells from the CHIKV infection, with the highest mean cell viability of $72 \%$ being shown by the ethanolic extract at $512 \mu \mathrm{g} \mathrm{mL} \mathrm{m}^{-1}$ (Fig. 2). Thus, the half-maximal effective concentration values (mean $\pm \mathrm{SD}, n=3$ ) for these three extracts were $236.5 \pm 3.5$, $411.4 \pm 22.2$, and $250.9 \pm 11.8$ $\mu \mathrm{g} \mathrm{mL}{ }^{-1}$, resp. To explore the possible mechanisms of the anti-CHIKV activity, a recombinant baculovirus, vAc-CMV-CHIKV NS-EGFP was constructed (Fig. 3a). As this vector can be transduced with high efficiency using the human bone marrow-derived cell line U-2 OS (19), we tested the anti-CHIKV replication activity of the plant extracts in vAc-CMV-CHIKV NS-EGFP transduced U-2 OS cells. Interestingly, only the ethyl acetate extract reduced the EGFP activity significantly $(p<0.001$, Fig. $3 b)$.

Ethanolic, methanolic, and water extracts were found to show strong inhibition on the cytopathic effect caused by CHIKV while ethyl acetate extract showed significant antiCHIKV replication activity in the replication inhibition assay. Thus, the anti-CHIKV activity of the ethanolic, methanolic, and water extracts might be mediated through other mechanisms such as membrane fusion blocking activity or inhibition of proteases synthesis, viral uncoating or cellular release of virions. Only ethyl acetate extract contained yet-to-be-identified phytochemical(s) that can block the replication mechanism of CHIKV. Betulinic

\section{vAc-CMV-CHIKV NS-EGFP}


Fig. 3. Anti-CHIKV replication activity of the leaf extracts of Syzygium myrtifolium. a) The recombinant baculovirus vAc-CMV-CHIKV NS-EGFP. CMV indicates the human cytomegalovirus-derived immediate early promoter; nsP1, nsP2, nsP3, and nsP4 indicate the replicon components of CHIKV. After the translational stop signal of nsP4 (Stop, the black triangle), a subgenomic promoter was inserted before the enhanced green fluorescent protein (EGFP). b) The vAc-CMV-CHIKV NS-EGFP transduced U-2 OS cells were treated with the ethanol (SM-ET), ethyl acetate (SM-EA), and water (SM-WA) extracts of Syzygium myrtifolium at 10, 20, and $40 \mu \mathrm{g} \mathrm{mL} \mathrm{m}^{-1}$. The fluorescent activity is expressed as mean \pm SD $(n=3)$. The asterisk denotes significant difference among the concentrations of an extract $(p<0.001)$ by one-way ANOVA test. 
and ursolic acids, which are the two triterpenoids found in the leaves of S. myrtifolium, have been reported to have broad-spectrum activity against many viruses, including human immunodeficiency, herpes simplex, hepatitis, and influenza viruses $(21,22)$. Further studies are needed to ascertain whether these triterpenoids or other phytochemicals in the leaves possess anti-CHIKV activity.

\section{CONCLUSIONS}

This study found that the leaf extracts of S. myrtifolium contained various classes of phytochemicals and possessed antioxidant, antibacterial, antifungal, and antiviral activities. The antioxidant activity of the leaf extracts of S. myrtifolium was evaluated based on the capacity of the extracts to scavenge DPPH radicals and peroxyl radicals, as well as the ability to reduce ferric ions to ferrous ions. Based on the results of correlation analysis, the polyphenols present in the leaves are likely to contribute to the antioxidant activities of the extracts. To the best of our knowledge, this is the first such study on the antimicrobial activity of S. myrtifolium against human pathogenic bacteria and yeasts. Alkaloids, terpenoids (triterpenoids and saponins), and polyphenols (anthraquinones, flavonoids, phenolics, and tannins) that are present in the leaves of S. myrtifolium are likely to account for the antibacterial and antifungal activities of this plant. Further work is necessary to identify the components which are active against the fungi and CHIKV, as well as the mechanisms of action of the active components. The findings from this study accentuate the potential of this plant as a source of bioactive compounds for pharmaceutical development.

Acknowledgements. - The study was supported by the research grant (MOST-107-2321-B-033-001) from the Taiwan Ministry of Science and Technology awarded to Tzong-Yuan Wu, the 2018-New Southbound Project scheme from the Taiwan Ministry of Education awarded to Tzong-Yuan Wu (Taiwan) and Nam Weng Sit (Malaysia), and the UTAR Research Publication Scheme (Vote no.: 6251/ S02) awarded to Nam Weng Sit. The authors thank Mr. Cheong Wei Ong for technical assistance.

\section{REFERENCES}

1. C. M. Boo, O. Kartini and C. L. Ou-Yang, 1001 Garden Plants in Singapore, $2^{\text {nd }}$ ed., National Parks Board, Singapore 2003.

2. A. H. Memon, Z. Ismail, A. F. A. Aisha, F. S. R. Al-Suede, M. S. Ridzuan Hamil, S. Hashim, M. A. Saeed, M. Laghari and A. M. Abdul Majid, Isolation, characterization, crystal structure elucidation, and anticancer study of dimethyl cardamonin, isolated from Syzygium campanulatum Korth, Evid. Based Complement. Alternat. Med. 2014 (2014) Article ID 470179; https://doi.org/10.1155/2014/470179

3. A. F. A. Aisha, Z. Ismail, K. M. Abu-Salah, J. M. Siddiqui, G. Ghahar and A. M. S. Abdul Majid, Syzygium campanulatum Korth methanolic extract inhibits angiogenesis and tumor growth in nude mice, BMC Complement. Altern. Med. 13 (2013) Article ID 168; https://doi.org/10.1186/1472-6882-13-168

4. A. F. A. Aisha, K. M. Abu Salah, Y. Darwis and A. M. S. Abdul Majid, Screening of antiangiogenic activity of some tropical plants by rat aorta ring assay, Int. J. Pharmacol. 5 (2009) 370-376; https://doi. org/10.3923/ijp.2009.370.376

5. I. I. Zakaria, N. H. Salin, A. Amanah, S. Othman, F. Khairuddin, M. H. Khawory, R. A. Wahab, M. R. A. Rahaman, P. P. Chern, N. A. Johari and H. Wahab, Potential antiviral compounds from Malaysian Plant Natural Product Repository and Database (MyNature50000) for DENV2, Biotechnol. Biotechnol. Equip. 33 (2019) 379-389; https://doi.org/10.1080/13102818.2019.1578184 
6. A. H. Memon, Z. Ismail, F. S. Al-Suede, A. F. Aisha, M. S. Hamil, M. A. Saeed, M. Laghari and A. M. Majid, Isolation, characterization, crystal structure elucidation of two flavanones and simultaneous RP-HPLC determination of five major compounds from Syzygium campanulatum Korth, Molecules 20 (2015) 14212-14233; https://doi.org/10.3390/molecules200814212

7. G. Pizzino, N. Irrera, M. Cucinotta, G. Pallio, F. Mannino, V. Arcoraci, F. Squadrito, D. Altavilla and A. Bitto, Oxidative stress: Harms and benefits for human health, Oxid. Med. Cell. Longev. 2017 (2017) Article ID 8416763 (13 pages); https://doi.org/10.1155/2017/8416763

8. World Health Organization, WHO Methods and Data Sources for Global Burden of Disease Estimates 2000-2016; https://www.who.int/healthinfo/global_burden_disease/GlobalDALY_method_2000_ 2016.pdf?ua=1; last access date February 29, 2020

9. F. Bongomin, S. Gago, R. O. Oladele and D. W. Denning, Global and multi-national prevalence of fungal diseases-estimate precision, J. Fungi (Basel) 3 (2017) Article ID 57; https://doi.org/10.3390/ jof3040057

10. C. R. Morrison, K. S. Plante and M. T. Heise, Chikungunya virus: Current perspectives on a reemerging virus, Microbiol. Spectrum 4 (2016) Article ID EI10-0017-2016 (14 pages); https://doi. org/10.1128/microbiolspec.EI10-0017-2016

11. J. B. Harborne, Phytochemical Methods. A Guide to Modern Techniques of Plant Analysis, $3^{\text {rd }}$ ed., Chapman and Hall, London 1998.

12. T. J. Herald, P. Gadgil and M. Tilley, High-throughput micro plate assays for screening flavonoid content and DPPH-scavenging activity in sorghum bran and flour, J. Sci. Food Agric. 92 (2012) 23262331; https://doi.org/10.1002/jsfa.5633

13. K. Pavithra and S. Vadivukkarasi, Evaluation of free radical scavenging activity of various extracts of leaves from Kedrostis foetidissima (Jacq.) Cogn., Food Sci. Hum. Wellness 4 (2015) 42-46; https://doi. org/10.1016/j.fshw.2015.02.001

14. H. Yang, Y. Dong, H. Du, H. Shi, Y. Peng and X. Li, Antioxidant compounds from propolis collected in Anhui, China, Molecules 16 (2011) 3444-3455; https://doi.org/10.3390/molecules16043444

15. Y. W. Heng, J. J. Ban, K. S. Khoo and N. W. Sit, Biological activities and phytochemical content of the rhizome hairs of Cibotium barometz (Cibotiaceae), Ind. Crops Prod. 153 (2020) Article ID 112612; https:// doi.org/10.1016/j.indcrop.2020.112612

16. Y. S. Chan, K. S. Khoo and N. W. Sit, Investigation of twenty selected medicinal plants from Malaysia for anti-Chikungunya virus activity, Int. Microbiol. 19 (2016) 175-182; https://doi. org/10.2436/20.1501.01.275

17. N. W. Sit, Y. S. Chan, S. C. Lai, L. N. Lim, G. T. Looi, P. L. Tay, Y. T. Tee, Y. Y. Woon, K. S. Khoo and H. C. Ong, In vitro antidermatophytic activity and cytotoxicity of extracts derived from medicinal plants and marine algae, J. Mycol. Med. 28 (2018) 561-567; https://doi.org/10.1016/j.mycmed.2018.07.001

18. G. Repetto, A. del Peso and J. L. Zurita, Neutral red uptake assay for the estimation of cell viability/ cytotoxicity, Nat. Protoc. 3 (2008) 1125-1131; https://doi.org/10.1038/nprot.2008.75

19. M.-K. Liu, J.-J. Lin, C.-Y. Chen, S.-C. Kuo, Y.-M. Wang, H.-L. Chan and T. Y. Wu, Topoisomerase II inhibitors can enhance baculovirus-mediated gene expression in mammalian cells through the DNA damage response, Int. J. Mol. Sci. 17 (2016) Article ID 931 (15 pages); https://doi.org/10.3390/ ijms17060931

20. M. Insanu, Z. M. Ramadhania, E. N. Halim, R. Hartati and K. R. Wirasutisna, Isolation of 5,7-dihydroxy, 6,8-dimethyl flavanone from Syzygium aqueum with its antioxidant and xanthine oxidase inhibitor activities, Pharmacogn. Res. 10 (2018) 60-63; https://doi.org/10.4103/pr.pr_59_17

21. L. Woźniak, S. Skąpska and K. Marszalek, Ursolic acid - a pentacyclic triterpenoid with a wide spectrum of pharmacological activities, Molecules 20 (2015) 20614-20641; https://doi.org/10.3390/molecules201119721

22. J. L. Ríos and S. Máñez, New pharmacological opportunities for betulinic acid, Planta Med. 84 (2018) 8-19; https://doi.org/10.1055/s-0043-123472 